Research Article

\title{
Research on the Influence of Industry-University-Research Cooperation Innovation Network Characteristics on Subject Innovation Performance
}

\author{
Mingxing Li $(\mathbb{D}$, Mengjuan Zhang $\mathbb{D}$, Fredrick Oteng Agyeman $\mathbb{D}$, \\ and Hira Salah ud din Khan \\ School of Management, Jiangsu University, Zhenjiang 212013, China \\ Correspondence should be addressed to Fredrick Oteng Agyeman; fredrickotengagyeman2@gmail.com
}

Received 27 May 2021; Revised 30 July 2021; Accepted 10 August 2021; Published 23 August 2021

Academic Editor: Isabella Torcicollo

Copyright $(2021$ Mingxing Li et al. This is an open access article distributed under the Creative Commons Attribution License, which permits unrestricted use, distribution, and reproduction in any medium, provided the original work is properly cited.

\begin{abstract}
The automobile industry serves as the primary industry for national development and also enhances manufacturing development strategies. Its source of power comes from the maturity and operational efficiency of the technology innovation network within the industry. Firstly, this paper takes the automobile industry of the Yangtze River Economic Belt as the research object and depicts the topological structure of the 1985-2015 Industry-University-Research Cooperation Innovation Network (IURCIN) from the perspective of space-time evolution. Then, based on the 2015 industrial network characteristic data, the paper analyses the impact of individual network characteristics such as intermediate centrality, structural hole limitation, and cooperation intensity on the innovation performance of the respective network. At the same time, it adds innovation activity, per capita gross regional product (GRP), and research and development (R\&D) fund input intensity as control variables in the quantitative analysis. The results show that the centrality and structural hole limitation significantly and positively affect the subject innovation performance. The cooperation intensity and the subject innovation performance have an inverted U-shaped relationship. The innovation activity has a positive effect on the subject's innovation performance. Furthermore, per capita GRP and R\&D expenditure intensity on the main innovation performance is not significant. Finally, the countermeasures and suggestions are put forward to promote the innovation performance of each subject in the IURCIN.
\end{abstract}

\section{Introduction}

Companies interact and collaborate more frequently with other organizations and become more dependent on each other to gain fuller access to strategic resources for innovation and to maximize their benefits. Universities and research institutions have also strengthened their partnerships with governmental organizations and private companies to commercialize their scientific and technological innovations, absorb social capital from the external environment, and keep pace with market changes. The exchange and cooperation between innovation subjects have become more frequent, gradually forming a model of industryuniversity-research cooperation. Over time, the model of University-Industry-Research Cooperation is gradually changing from the simple linear model of "point $\longrightarrow$ point" to the complex network model of "point $\longrightarrow$ line $\longrightarrow$ surface." With the advantages of information sharing, risk sharing, and cost reduction, the Industry-UniversityResearch Collaborative Innovation Network is becoming an optimal model for solving technological innovation problems in the context of a changing market environment [1]. The idea of making good use of innovation networks to obtain innovation resources to promote industries' innovation performance has become an inevitable choice for enterprises to implement regional, international, and open innovation [2]. The innovation network is also an inevitable field for universities and research institutions to reach sustainable development. This point of view has been unanimously recognized by both academic and practical 
circles in China. This study finds answers to the following two research questions based on collaborations' key benefits the industry and university generate: what is the pattern of the topological structure of the automobile industry of the Yangtze River Economic Belt Industry-University-Research Cooperation Innovation Network from the perspective of space-time evolution from 1985 to 2015? And, what is the impact of individual network characteristics on intermediate centrality, structural hole limitation, and cooperation intensity on the innovation performance of the IndustryUniversity-Research Cooperation Innovation Network?

\section{Literature Review}

Extant studies have been conducted on network characteristics, and findings indicate that there are two main network characteristics levels of analysis: overall network characteristics and individual network characteristics. From the perspective of overall network characteristics, the innovation performance of subjects in the overall network is studied mainly in terms of two indicators of small-world network characteristics-clustering coefficient and characteristic path length. Small-world networks can generate faster information flow due to shortcuts between nodes $[3,4]$. [5] studied small-world network model on the influence of agglomeration coefficient and characteristic path length on the knowledge transfer activities of industryuniversity-research cooperative innovation networks. The researchers concluded that the path length and concentration degree among innovation subjects should be kept within a specific range and should not be too large or too small. [6] explored the relationship between small-world network structural features and firms' innovation performance, pointing out that path length was negatively correlated with firms' innovation performance. The study concluded that the relationship between agglomeration and small-world $Q$ values and firms' innovation performance was inverted U-shaped. [7] analyzed the relationship between network characteristics and firm innovation performance. The study focused on the Chinese automotive industry's strategic alliances' networks and used agglomeration coefficient, accessibility, and structural hole as explanatory variables. It also selected the intermediate centrality, network density, and central potential as control variables. Their findings showed that neither the agglomeration coefficient nor the accessibility nor the interaction term of the two have any significant effect on improving the innovation performance of firms.

Based on the State Intellectual Property Office of the People's Republic of China (SIPO) database, [8] examined the impact of network structure characteristics on firms' innovation performance in China's ICT sector, using agglomeration coefficient and accessibility as independent variables. Their findings show that the clustering coefficient and accessibility have significant positive effects on firms' innovation performance. In both the current and lagged periods, the interaction term of clustering coefficient and accessibility significantly and positively affects firms' innovation performance in the lagged period. [9] explored the effect of small-world network characteristics on innovation output, using a patent collaboration network for nanotechnology in China. Their findings show that networks with small-world characteristics, high agglomeration, and low average path length coexist in an inverted U-shaped relationship with the number of patent applications and that R\&D personnel need to maintain a balance with collaboration between inner circle personnel distant developers.

The individual network characteristics are also categorized into individual network structure characteristics and relationship characteristics. Also, some scholars have conducted a series of studies concerning the breadth and intensity of cooperation. [10] conducted an empirical analysis based on transfer costs and network structure using multinational company data. Findings suggest that in periods of high technological uncertainty, increased cooperation intensity hinders firm performance; lower cooperation intensity helps firms obtain nonduplicative information and thus capture emerging technologies and market trends. [11] used a sample of 77 telecom equipment manufacturers' patent data and findings show that the diversity (breadth of cooperation) of an innovation agent's partners can increase its innovation performance. In addition, the density of the firm's network can enhance its diversity.

[12] analyzed the influence of network characteristics on knowledge integration and technological innovation in industry-academia-research cooperative innovation networks by using structural equation modeling in two dimensions: network structure characteristics (including network density, network scope, partner diversity, and network centrality) and network relationship characteristics (including interaction frequency, linkage duration, network stability, and trust), respectively. The results show that: network structural characteristics have a significant positive effect on knowledge integration but not on technological innovation; network relationship characteristics have a significant positive impact on knowledge integration and technological innovation. [13] constructed a patent collaboration network and analyzed the relationship between network characteristics and innovation performance using a sample of joint patent applications in the Canadian nano industry. Their findings indicated that more central inventors and stars in the research team positively influence the patent quality, while repeated collaboration has a negative impact.

Studies on the centrality and structural holes explored by researchers in the contemporary periods show that weak ties (poor relationship strength) can transfer simple information effectively. In contrast, more complex information relies on strong ties (strong relationship strength). Thus, the strength of network relationships affects innovation performance $[14,15]$. [16] analyzed the impact of structural holes on corporate innovation performance based on data from the SDC Platinum database, the China Intellectual Property Office, and industry reports, and using a consortium of Chinese domestic audiovisual equipment manufacturers as a research object. The results show that the relationship between a firm structural hole and a firm innovation performance is significantly positively correlated, while efficiency, constraint, and hierarchy have no significant effect on the acquisition of patents by firms. 
[17] studied a collaborative innovation network of industry-university-research marine energy research institutions. Their findings showed that having the highest centrality and the smallest structural voids positively affected promotion of the innovation output. However, the effect of intermediate centrality was not significant. [18] analyzed the characteristics of the IURCIN of Guangxi's electronic information industry based on the number of network nodes, the number of edges, the average distance, and the individual structural holes and centrality, and further explored the influence of network characteristics on regional knowledge diffusion. Their research results showed that network nodes and network edges had the most substantial effect on knowledge diffusion. The structural holes and average distance were the second strongest.

[19] used China's electronic industry information as the research object and jointly applied for the invention patents as the research sample, thus constructing an innovation network and analyzing the network characteristics and its evolution on the innovation performance of enterprises. The study results show that China's electronic industry information innovation network has a "core-edge" pattern with a significant "small-world network" characteristic. Also, the point-centredness and structural holes have a significant positive impact on improving the innovation performance of the subject.

Recently, scholars have begun to explore the impact of proximity in spatial distance and knowledge perception of innovation subjects on innovation performance. Results confirm that proximity centrality (location variable) has a more or less significant effect on innovation performance $[20,21]$. [22] used the industrial park enterprises as the research object to analyze the relationship between geographical and cognitive proximity in addition to the innovation performance of enterprises. Their findings showed that both geographic and cognitive proximity positively affect the innovation performance of enterprises in industrial parks. $[23,24]$ explored the impact of geographical proximity on the formation of technological innovation partnerships and their innovation performance in universities. They employed patents developed in collaboration between higher education institutions in China as a research sample. Their findings showed that the role of geographical proximity on the formation of different types of technology partnerships and collaborative innovation performance are unequal.

[25] also analyzed the impact of network proximity and geographical proximity on knowledge transfer performance in a network using a strategic alliance in the Chinese biopharmaceutical industry. Their findings showed that both made a positive contribution to knowledge transfer performance. Also, geographical proximity was significant, while network proximity was not.

2.1. Summary of Literature Review. The literature reviewed above reveals that studies on the utility characteristics of industry-university-research cooperation innovation networks have been categorized into two-overall network characteristics and individual network characteristics. Studies on overall network characteristics mainly focus on the two small-world characteristics: clustering coefficient and average path length. The individual network characteristics are pointed primarily for degree centrality, structural hole, centrality, etc. This study aims to contribute to knowledge and broaden the in-depth investigations on the innovation network of industry-university-research cooperation innovation network and explore the utility of proximity. In this study, 11 provinces and cities in the Yangtze River Economic Belt are the spatial scope. The study used 1985-2015 data for analysis to explore the influence of some individual network characteristics on the innovation performance of the subjects in the network.

\section{Data Sources and Processing}

3.1. Data Processing. First of all, in order to adapt to the new round of rapidly developing scientific and technological revolution and industrial revolution, on March 25, 2015, China officially adopted "Made in China 2025," which aims to accelerate the construction of China's manufacturing innovation network, with the automotive industry as one of the ten major fields. It has become a key breakthrough area in China's manufacturing industry. Also, the Yangtze River Economic Belt covers 11 provinces in the east and west, and the construction of the Yangtze River Economic Belt occupies a critical strategic position in China's regional economic development pattern. Hence, this paper selects China's Yangtze River Economic Belt automobile industry as the object of industrial network research.

Secondly, the "Patent Information Service Platform for Key Industries," organized by the State Intellectual Property Office of the People's Republic of China (SIPO), hosted by the State Intellectual Property Publishing House and coorganized by a number of institutions, is dovetailed with the SIPO patent database and updated in real time, which is scientifically based and comprehensive. The service platform handles all the patents in the ten key national industries since 1985; simultaneously, the ten key industries are professionally classified by industry, respectively. The patents are apportioned into four categories: invention patents, utility models, designs, and invention licenses. Therefore, with respect to the sample size and selection accuracy, the key industry information service platforms are selected as the sample data source in this paper.

Patent collaboration applications and direct innovation activities between industry and research are widely used as an empirical indicator to study collaborative innovation [26]. In cooperating to apply for patents, the innovation subjects of industry-university-research cooperation form an informal cooperation network. The network formation provides an important channel for acquiring, transferring, and sharing knowledge of each issue. This paper selects the automotive industry in the Yangtze River Economic Belt as the research object. It also used the data on joint patent applications as the research sample. It aims to portray the evolutionary trend of the innovation network of industryuniversity-research cooperation in the automotive industry 
in the Yangtze River Economic Belt and analyze the impact of the network characteristics on the innovation performance of the subject.

The search path for the patent data required for the paper is as follows: first, enter the "Key Industry Patent Information Service Platform," click and select "Automotive Industry", and search the six major sectors of engine, chassis, body, electrical equipment, fuel (oil), and other vehicles in turn. Search for Chinese patents. Set search fields: filing date $=1985$ to 2005 ; an applicant (patentee $)=($ company or university or college or research or centre or factory or group); country and province code: 31 or 32 or 33 or 34 or 36 or 42 or 43 or 51 or 53 or 52 or 85 , representing the 11 provinces of the Yangtze River Economic Belt (Shanghai, Jiangsu, Zhejiang, Anhui, Jiangxi, Hubei, Hunan, Sichuan, Yunnan, Guizhou, and Chongqing). The period chosen for the study spans from 1985 to 2015 . There was a lag of one to two years from the date of the patent application to disclosure.

Secondly, the number of applications (patent rights) is greater than or equal to 2, including organizations such as companies and universities. Hence, this paper studies the industry-university-research cooperation and innovation network of the automotive industry in the Yangtze River Economic Belt, referring to the screening method of [27] and searching patent information according to the national and provincial codes of 11 provinces and cities in the Yangtze River Economic Belt. After setting the search formula, the data of the patents with cooperative relationships were filtered and downloaded. Patent information mainly includes patent name, application date, application number, the applicant (patentee) and inventor (design), etc. The downloaded cooperative patents were then sorted, and those with the same patent name and application number were deleted. Finally, 13,187 patents were obtained for joint applications of university-industry-research cooperation. This part of the data was mainly used to construct the innovation network of university-industry-research cooperation and draw the network topology map.

In order to obtain the patent application data of each innovation entity in 2015, this study downloaded all patent data of three categories, including invention patents, utility model patents, and design patents of the automobile industry in the Yangtze River Economic Zone in 2015 separately, totaling 54.67 million patent information and then arranged the patent application volume of each innovation entity in 2015 through Excel. This part of the data is mainly used to analyze the dependent variables in the utility characteristics of the IURCIN. The utility characteristics help to explore the relationship between network characteristics and the innovation performance of the subject. Finally, with the help of the China City Statistical Yearbook and the China Science and Technology Statistical Yearbook, the corresponding data on indicators such as GRP per capita and R\&D funding intensity in each region of the Yangtze River Economic Zone were obtained. The data aims to assist in performing regression analysis on the control variables concerning the utility characteristics.
3.2. Building a Collaborative Innovation Network. According to social network theory, a network consists of two major elements: nodes and links. This paper takes the automotive industry in the Yangtze River Economic Zone as the research object. It extracts the innovation subjects such as enterprises, universities, and research institutions in the automotive industry as the nodes in the network and the relationship arising from the cooperation between the innovation subjects in applying for patents as the links.

First, the 13,187 collaborative patent applications collected were divided into 31 data by year using Excel software. The annual collaborative patent application data were collated and converted into a 2-module numerical matrix $m \times n$. Afterward, the 2-module numerical matrix was converted into a 1-module numerical matrix $m \times m$ using Excel. The UCINET statistical software was then used to analyze the 1-mode numerical matrix $m \times m$ over the years to obtain network characteristics such as network density, clustering coefficients, degree centrality, structural holes, etc. Finally, the NetDraw visualization tool was used to draw the relevant network maps.

This study processed and constructed the patent data of two or more innovation subjects and a collaborative network. The process of network construction is illustrated in Figure 1, where 1, 2, 3, and 4 denote each collaborative patent, and $A, B, C, D, E, F, G, H$, and $I$ denote different applicants (patent owners), i.e., individual innovation subjects.

\section{Empirical Analysis}

4.1. Network Topology. The various subjects in the innovation network of the automotive industry in the Yangtze River Economic Zone are the "points" in the network, and the links generated by the cooperation between them constitute the "lines." Combining "points" and "lines" jointly constructs the innovation network of the automotive industry-university-research cooperation in the Yangtze River Economic Belt. This paper compares the overall topology of the mapped cooperative innovation network over the years, which can more intuitively show the complex correlation characteristics of the network and the evolution trend over time.

This study used the development history of the innovation network of industry-university-research cooperation in the automotive industry in the Yangtze River Economic Belt. The development history is divided into four stages. Also, the visualization tool NetDraw was used to draw the complex network topology for five-year intervals, including 1985, 2000, 2005, 2010, and 2015, as shown in Figure 2.

As can be seen from the topology of the innovation network of the industry-university-research cooperation in the automotive industry in the Yangtze River Economic Belt over the years, the network presents a gradual expansion in scale. The correlation between network nodes is gradually complex, the overall network connectivity is steadily enhanced, and the network appears to be characterized by cohesive subgroups. Before 2000, the network was marked by a low level of connectivity, i.e., fewer nodes and fewer 

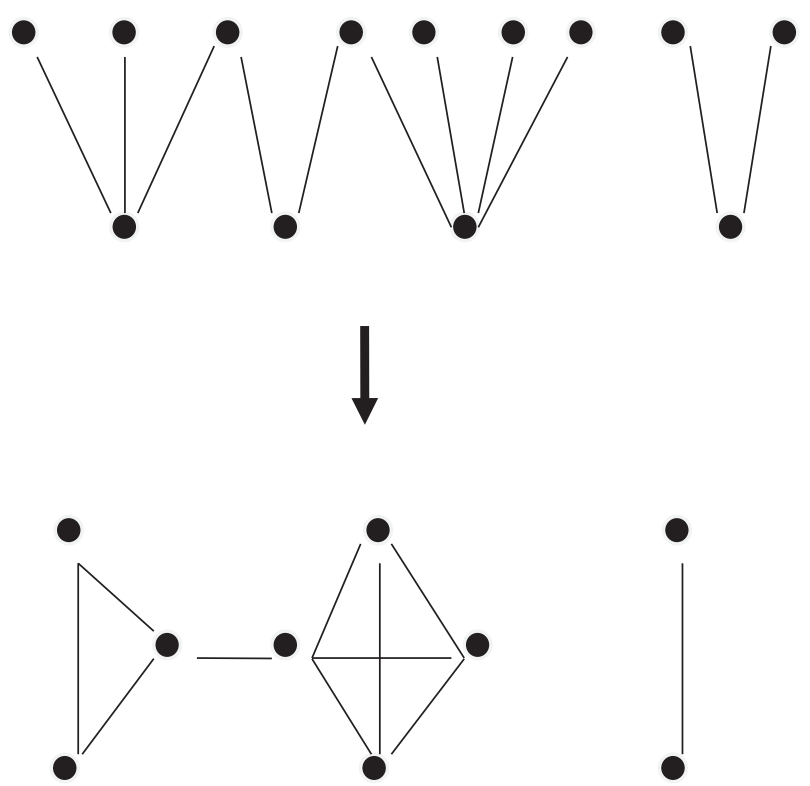

FIgURE 1: Collaborative network map construction. Source: [8].

links. There were very few innovation agents in the automotive industry in the Yangtze River Economic Zone. After 2000, the number of innovation subjects in the automotive industry in the Yangtze River Economic Zone began to increase. The complexity and connectivity of the network expanded. The strength of the relationship between some innovation subjects in the network also increased, and subnetworks with apparent clustering emerged.

The analysis of the network topology diagram reveals that the scale of the innovation network of industry-university-research cooperation in the Yangtze River Economic Belt reached its peak in 2015. Therefore, this paper mainly selects the 2015 network with the largest network scale and complexity to analyze the influence of network node characteristics on the innovation performance of the subject.

4.2. Regression Analysis and Hypothesis. The linear regression model can describe and reflect the relationship among independent variables, moderating variables, and dependent variables. In conducting the regression analysis in this study, all the variables involved in the interaction were structured to be mean-centered to avoid the potential collinearity problem. However, because of the different data sets used in this study, negative binomial regression is considered because it can capture over-dispersed count data when the conditional variance exceeds the conditional mean. This study focussed on the negative binomial regression model for analysis. Negative binomial regression is a generalization of Poisson regression that lowers the Poisson model's restrictive assumption that variance equals mean. It has been established that for nonnegative discrete data, a negative binomial regression model is the most effective. It gives a more accurate indication of the direction of influence between variables and the strength of the effect. [28].

\subsubsection{Hypothesis Proposed}

(1) Intermediate Centrality. Intermediate centrality measures the probability that a node in a network is on a "shortcut" to any two other nodes accessible to each other. Innovation agents with high intermediate centrality indicate that they are more likely to be located on "shortcuts" between different nodes. They have more control over the flow of information and resources between nodes. It helps to gain access to new knowledge, technology, and information. According to [29], R\&D personnel with high intermediate centres can gather valuable information and knowledge through multiple channels, which not only helps $R \& D$ personnel access and control resources but also helps them increase their influence and dominance over other subjects. [30-32] showed that the intermediate centrality of networks has a significant positive effect on firms' technological innovation performance, helping them obtain more network connections and thus more reliable and diversified resources [33]. [18] analyzed the relationship between intermediate centrality and knowledge diffusion using an IURCIN in electronic information in Guangxi. Results show that the greater the intermediate centrality of a collaborative network, the better the diffusion of knowledge.

A summary can be drawn from the studies that the higher the intermediate centrality of innovation agents in a network, the stronger their ability to acquire and integrate new resources. And, the more advantageous they are in controlling the flow of new resources, which affects their innovation performance. Based on the above analysis, this paper proposes the following hypothesis:

$\mathrm{H} 1$ : Intermediate centrality has a positive effect on the innovation performance of network subjects.

(2) Structural Hole Limit System. Suppose there is no direct connection between two subjects connected to an innovation subject. In that case, that subject acts as a bridge, having "access to information and control of benefits" and a competitive advantage over other subjects in the same position. In other words, as the number of structural holes increases incrementally, the more resources the innovation agent can control and utilize, contributing significantly to improved innovation performance. $[18,34,35]$ argue that firms that occupy structural holes can better adapt to new environments and access more nonredundant knowledge and diverse resources to facilitate improved firm performance. However, too many structural holes in the network hinder the coordination of knowledge between subjects. This hindrance is detrimental to their innovation; it prevents the formation of trust mechanisms between network subjects and reduces the willingness to share knowledge. The unwillingness to share knowledge makes it more difficult for subjects to access their external resources. In an IURCIN, the subject needs to actively search for knowledge through network relationships to obtain new resources needed for its development. It also helps to achieve effective knowledge transfer through close cooperation with network members, on the other hand. 

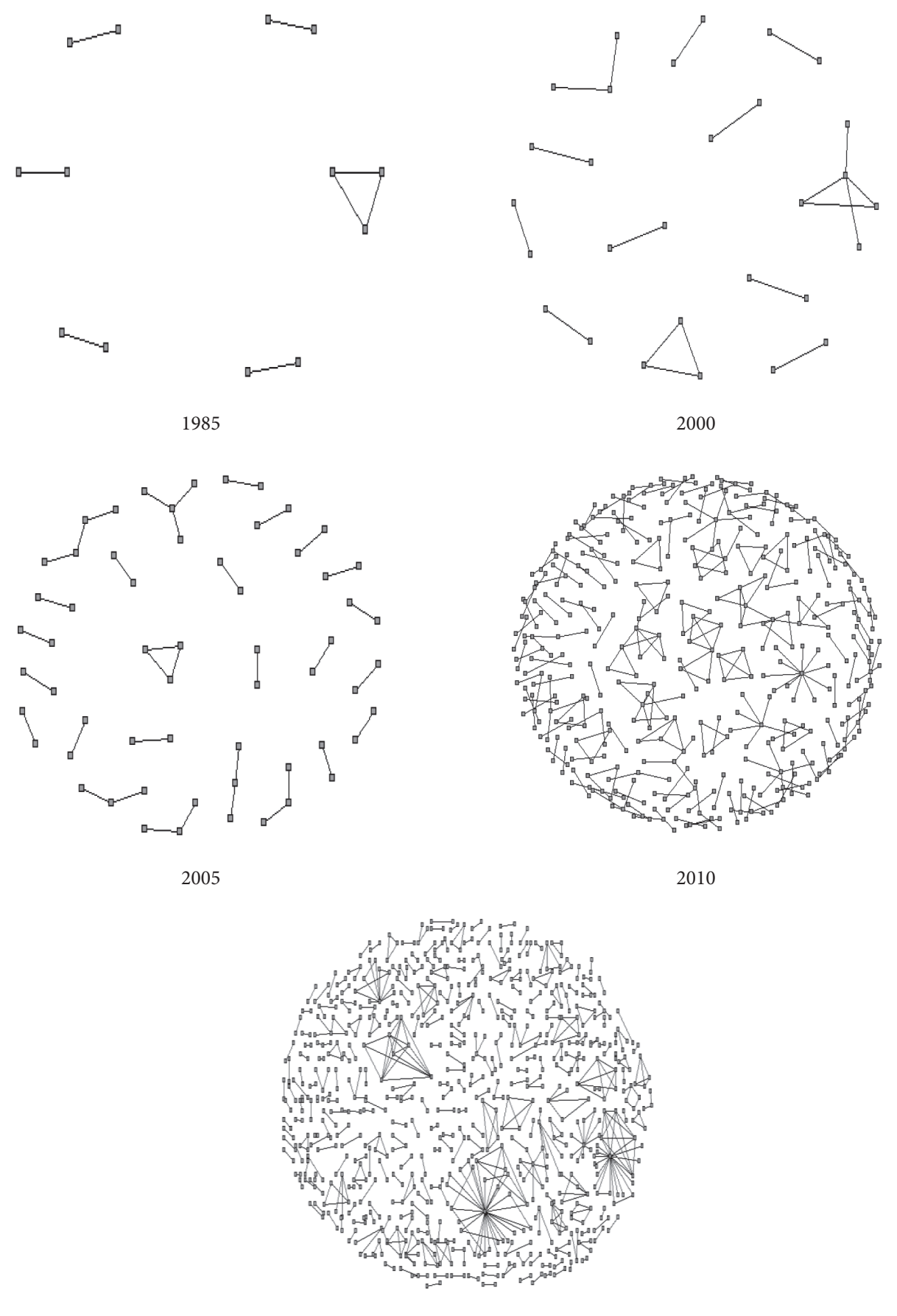

2015

FIGURE 2: The overall topology of the industry-university-research cooperation and innovation network in the Yangtze River Economic Belt. (a) 1985. (b) 2000. (c) 2005. (d) 2010. (e) 2015.

Structural holes have the dual characteristics of knowledge search and knowledge transfer contradiction. Thus, the relationship between the structural and the subject's innovation performance is more complex, so the relationship between structural and innovation performance is not necessarily positive. [36] showed that structural holes negatively impact firms' innovation performance based on 222 high-tech enterprises in Shanghai. However, [28] had both positive and negative results in their studies on the impact of structural holes on firms' innovation performance.
Based on the above analysis, the following hypotheses are formulated in this paper.

$\mathrm{H} 2$ : There is a U-shaped relationship between the structural hole limit system and the innovation performance of the subject.

(3) Intensity of Cooperation. According to social network theory, the intensity of cooperation is the average number of times a specific subject cooperates with other subjects. In the process of industry-university-research collaboration, 
knowledge transfer is influenced by the knowledge distance and the type. Knowledge distance refers to the distance between cooperative subjects on knowledge. If the knowledge distance is too close, it leads to the lack of heterogeneous strategic resources, which is not conducive to innovation. If the knowledge distance is too far, it is not conducive for saving transaction costs and establishing trust mechanisms between cooperative subjects. In other words, there is an optimal threshold for the intensity of cooperation between subjects, which enables the exchange of information and collaboration between cooperating subjects based on mutual trust, thus better utilizing the positive effect of network knowledge on the innovation performance of subjects. [10] shows that low collaboration intensity helps firms to obtain nonduplicative information to capture emerging technologies and market trends.

[37] found that the intensity of cooperation contributes to the flow of knowledge between firms and the construction of innovation platforms. [38] concluded that the intensity of strong collaboration has a significant positive effect on firm innovation performance. However, in the process of industryuniversity-research cooperation, the corresponding innovation resources can only be effectively acquired through frequent exchanges for tacit knowledge. Collaboration between subjects inevitably has transaction costs. When the intensity of cooperation is small, the transaction cost is low. The low intensity of cooperation indicates the absence of in-depth collaboration between cooperative subjects. When the intensity of cooperation is large, it is possible to establish an effective trust mechanism among subjects. The resources that can be obtained subsequently increases when the marginal transaction cost and resource benefits reach parity. The continued increase in the intensity of cooperation will increase the cost of knowledge transfer, which is ultimately detrimental to the output of innovation results. Based on the above analysis, this paper puts forward the following hypothesis:

$\mathrm{Hb} 2$ : There is a U-shaped relationship between the intensity of cooperation and the innovation performance of the subject.

\subsubsection{Variable Selection}

(1) Dependent Variable. According to the research results of [39-41], the number of patent applications is the most widely used indicator to measure the innovation performance of a subject. The automotive industry is essentially a high-tech industry, which is knowledge- and technologyintensive and usually uses patents to reflect the results of its knowledge creation, which invariably contributes to intellectual property protection. Combined with existing research by scholars, this paper uses patent applications (Pat) as the innovation output outcome quantity of each subject, aiming to measure the respective innovation performance.

\section{(2) Independent Variables.}

(1) Intermediate centrality
The intermediate indicator centrality aims to measure how a node in the network lies on the shortest path between other nodes, i.e., the extent to which the node controls resources. Equation (1) explains the intermediate centrality:

$$
\mathrm{INC}_{i}=\sum_{j}^{n} \sum_{k}^{n} \frac{g_{j k(i)}}{g_{j k}},
$$

Where $j \neq k \neq i$ and $j<k$., $g_{j k}$ denotes the number of shortest paths that exist for any two nodes in the network. $g_{j k(i)}$ indicates the number of shortest paths that exist and pass through any two nodes in the network, the ratio $g_{j k(i)} / g_{j k}$ of the two paths is the probability that the node is on the shortest path between any two other points in the network, i.e., the intermediate centrality of that point.

(2) Structural hole limit system

A well-known scholar, Ronald Stuart Burt, introduced the concept of structural holes, emphasizing that occupants of structural hole positions have a definite advantage in accessing information and controlling resources in the network, which helps them enhance their innovation capabilities [42]. A "structural hole" is a gap in the social network, where one or some nodes in the social network are directly connected to some nodes but not to others. There is no direct relationship, or the connection is broken, and the network as a whole looks like a cave. Two innovation agents in a collaborative network are not directly linked to each other but try to connect through a third party. The network position occupied by the third party (innovation agent) constitutes a structural hole. Structural hole indicators mainly include effective size, efficiency, limit system, and hierarchy, with the limit system indicators being the most commonly used [43]. The structural hole limit system is elaborated by equation (2):

$$
\mathrm{CON}_{t}=\sum_{j}\left(p_{i j}+\sum_{q} p_{i q} p_{q j},\right.
$$

where $j \neq q \neq i, p_{i q}$ is the proportion of the total relationship $q$ invested in $i$ out of the total relationship inputs, and the same for $p_{q j}$ and $Y p_{i j}$.

(3) Intensity of cooperation

Cooperation intensity is related to the average number of times a subject cooperates with other subjects and is characterized by not dividing the sum of the total number of point degrees of the nodes of the re-edged network by the node degree centrality. The magnitude of cooperation intensity can reflect the frequency of knowledge exchange between subjects in the network. 
(3) Control Variables.

\section{(1) Innovation activity}

The level of innovation activity of a particular innovation subject is a direct reflection of its innovation capacity. This study used the total number of times a subject participated in the collaborative innovation within 1985-2015. It was used to measure the innovation activity of a subject. This indicator was used to control the variability in the innovation capacity of individual subjects in the network. The specific calculation process used is as follows: firstly, the year under observation is determined as 1985-2015; then, the number of times each subject in the network appears in the cooperation network in that year is calculated, and its innovation activity in a year is recorded as 1 , otherwise as 0 . The accumulated value is recorded as the innovation activity of each subject.

(2) GRP per capita

GRP per capita (gross regional product) is an essential indicator in economics to measure the economic development of a country or region and is one of the criteria to measure the standard of living of the people in an area. The GRP per capita for the cities in which the subjects in the network are located is used to control the impact of the level of economic development of the cities concerning their innovation activities.

(3) R\&D investment intensity

$\mathrm{R} \& \mathrm{D}$ investment intensity is measured as the ratio of $\mathrm{R} \& \mathrm{D}$ expenditure to GRP per capita. It is an important indicator to measure the level of scientific and technological development of a country or region. Its intensity reflects the level of scientific and technical strength and core competitiveness. This paper measures the level of science and technology development in the areas where the innovation agents are located. In terms of R\&D funding intensity, it controls the impact of the level of science and technology development in different regions on the innovation activities of each agent in the network. This paper uses government data on S\&T expenditure as R\&D funding input. Table 1 shows the variable selections and their measurements.

4.2.3. Model Setting. The dependent variable involved in this empirical study is the number of patent applications by the subject Pat $\in N^{*}$. It is a nonnegative integer set, which is of the counting type. The innovation capacity of the individual innovation subjects in the network varies widely. With unequal variance and mean values of the number of patents, it makes the data too discrete to apply to an ordinary least squares (OLS) linear regression model, as it may lead to invalid, nonconsistent, and biased parameter estimates [36]. The Poisson distribution is also unsuitable as it may underestimate the standard deviation of the parameters and overestimate the significance level. It has been shown that for nonnegative discrete data, a negative binomial regression model is the most effective. It gives a more accurate indication of the direction of influence between variables and the strength of the effect [28]. Therefore, negative binomial regression was used as the research model for this paper. The overall regression model for this study was developed as follows:

$$
\begin{aligned}
\mathrm{Pat}_{1}= & f\left(\beta_{0}+\beta_{1} \mathrm{INC}+\beta_{2} \mathrm{INC}+\beta_{3}(\mathrm{CON})^{2}+\beta_{4} \mathrm{COS}\right. \\
& \left.+\beta_{5}(\mathrm{COS})^{2}+\beta_{6} \mathrm{INA}+\beta_{7} \mathrm{GRP}+\beta_{8} R \& D\right)+\varepsilon_{i},
\end{aligned}
$$

where $i$ denotes the subject of innovation, and $\beta_{1}, \beta_{2}, \beta_{3}, \beta_{4}$, $\beta_{5}, \beta_{6}, \beta_{7}$, and $\beta_{8}$ are the regression coefficients of the variables, respectively. And, $\varepsilon_{i}$ represents the random error term.

\subsubsection{Analysis of Results}

(1) Descriptive Statistics. This paper selects the 2015 network (whose network size is the largest in terms of complexity) to analyze the impact of network characteristics on the innovation activities of subjects. The core reasons for selecting the 2015 network are as follows: firstly, some innovation subjects were removed due to the unavailability of data on GRP and R\&D expenditure; for instance, Guizhou Cenxiang Resource Technology Co., Ltd., which belongs to the Guizhou Qiandongnan Miao and Dong Autonomous Prefecture, is not covered in the China Urban Statistical Yearbook, while the statistical bureau of the Prefecture also does not list the relevant data in detail. Secondly, as there is some cross-regional cooperation among the Yangtze River Economic Belt subjects, issues outside the Yangtze River Economic Belt were also removed, such as the State Grid Corporation in Beijing. Hence, the final sample size obtained for this study is 704 subjects in the innovation network of industry-university-research cooperation in the automotive industry in the Yangtze River Economic Belt.

Table 2 indicates the result of the descriptive statistics and correlation coefficients. The descriptive statistics of the variables in Table 2 show that the minimum value and the number of applications for patents is 1 . The maximum is 390 , and the variance of the number of patents is much larger than the mean, indicating that the number of patent applications shows excessive dispersion and that the number of subjects with fewer applications accounts for a higher proportion of the overall number of network subjects. The mean and standard deviation of intermediate centrality are only 0.0002 and 0.002 , respectively, which shows that the intermediate centrality of network nodes is low, indicating that the overall connectivity in the industry-academia-research network of the automotive industry in the Yangtze River Economic Zone is low. The subjects are below standards in terms of information exchange and resource control capability.

Most of the cooperation is "point-to-point," and even the subnetworks with more than three members are mostly 
TABLE 1: Selection of variables and measurement.

\begin{tabular}{|c|c|c|c|c|}
\hline Variables & Name & Code & Meaning & Measurement \\
\hline \multirow[b]{2}{*}{$\begin{array}{l}\text { Dependent } \\
\text { variable }\end{array}$} & $\begin{array}{l}\text { Number of patent } \\
\text { applications }\end{array}$ & Pat & $\begin{array}{l}\text { The output of the main innovation } \\
\text { outcome, i.e., innovation performance }\end{array}$ & $\begin{array}{l}\text { Number of patent applications in the current } \\
\text { period }\end{array}$ \\
\hline & $\begin{array}{l}\text { Intermediate } \\
\text { centrality }\end{array}$ & INC & $\begin{array}{l}\text { The degree of centrality of the subject in } \\
\text { the network }\end{array}$ & $\begin{array}{l}\text { The probability that a subject is on the shortest } \\
\text { path between any two other subjects in the } \\
\text { network }\end{array}$ \\
\hline \multirow{3}{*}{$\begin{array}{l}\text { Independent } \\
\text { variables }\end{array}$} & $\begin{array}{l}\text { Structural hole } \\
\text { limit system }\end{array}$ & $\mathrm{CON}$ & $\begin{array}{l}\text { The extent to which the subject occupies } \\
\text { the position of the "bridge" }\end{array}$ & Subjects in the network limit system \\
\hline & $\begin{array}{l}\text { Intensity of } \\
\text { cooperation }\end{array}$ & $\cos$ & $\begin{array}{l}\text { Average number of times a subject } \\
\text { cooperates with other subjects }\end{array}$ & $\begin{array}{c}\text { Sum of the total number of point degrees of the } \\
\text { nodes of the network without deduplication/ } \\
\text { node degrees }\end{array}$ \\
\hline & Innovation activity & INA & $\begin{array}{l}\text { The extent to which subjects are active in } \\
\text { innovation in the network }\end{array}$ & $\begin{array}{c}\text { Number of times the subject of innovation } \\
\text { appeared between } 1985 \text { and } 2015\end{array}$ \\
\hline \multirow{2}{*}{$\begin{array}{l}\text { Control } \\
\text { variables }\end{array}$} & GRP per capita & GRP & $\begin{array}{c}\text { The level of economic development of the } \\
\text { city where the innovation subject is } \\
\text { located }\end{array}$ & Total regional output/total population \\
\hline & $\begin{array}{l}\mathrm{R} \& \mathrm{D} \text { investment } \\
\text { intensity }\end{array}$ & $\mathrm{R} \& \mathrm{D}$ & $\begin{array}{l}\text { The level of technological development of } \\
\text { the city where the innovation subject is } \\
\text { located }\end{array}$ & $\begin{array}{l}\text { Science and technology expenditure in } \\
\text { government expenditure/GRP }\end{array}$ \\
\hline
\end{tabular}

TABLE 2: Descriptive statistics and correlation coefficients of variables $(N=704)$.

\begin{tabular}{|c|c|c|c|c|c|c|c|c|c|c|c|}
\hline Variables & Mean & Std. & Min & Max & Pat & INC & $\mathrm{CON}$ & $\mathrm{COS}$ & INA & GDP & R\&D \\
\hline Pat & 11.670 & 33.513 & 1 & 390 & 1 & & & & & & \\
\hline INC & 0.0002 & 0.002 & 0 & 0.055 & 0.492 & 1 & & & & & \\
\hline $\mathrm{CON}$ & 1.052 & 0.132 & 0.547 & 1.215 & -0.218 & -0.244 & 1 & & & & \\
\hline COS & 3.452 & 11.791 & 0.4 & 238 & 0.434 & 0.064 & -0.019 & 1 & & & \\
\hline INA & 2.376 & 2.172 & 1 & 13 & 0.505 & 0.241 & -0.233 & 0.173 & 1 & & \\
\hline GRP & 82243.30 & 30661.93 & 4277 & 131695 & 0.011 & 0.039 & 0.005 & -0.079 & 0.117 & 1 & \\
\hline$R \& D$ & 0.006 & 0.003 & 0.001 & 0.015 & 0.005 & 0.021 & 0.021 & -0.003 & 0.092 & 0.376 & 1 \\
\hline
\end{tabular}

closed. This outcome is not conducive for the transfer of resources among the subjects in the network. The mean value of cooperation intensity is 3.4554 , and the standard deviation is 11.79893 , indicating a large difference in the cooperation intensity of each subject in the cooperation and innovation network of the automotive industry in the Yangtze River Economic Zone. Table 2 further presents the Pearson correlation coefficient results of the independent and control variables in the regression model. From Table 2, it can be seen that the variables' absolute values and their correlation coefficients are all below 0.6 , indicating that the regression model does not have serious multicollinearity problems and can proceed to the subsequent regression analysis.

4.2.5. Analysis of Regression Results. This paper uses a stepwise regression approach. Seven hundred and four subjects within the Yangtze River Economic Zone in 2015 were used to examine the impact of two independent variables, intermediate centrality, and structural hole limit system, on the innovation performance of subjects, and the results of the analysis are presented in Table 3.

(1) From the analysis, it can be seen that the values of the five models correspond to a significance level $p$ value of less than 0.01 , indicating that the models are highly significant. The best model is model 4 , with a decidable coefficient of $52.55 \%$, meaning that the overall explanatory power of the model is good.

(2) From model 1, the coefficients of intermediate centrality are positive. The significance of the $p$ value is less than 0.01 , indicating that intermediate centrality has a significant positive effect on the innovation performance of the subject. Therefore, hypothesis $\mathrm{H} 1$ is confirmed. The higher the intermediate centrality, the better the access to and control over the resources in the network, which in turn helps to improve innovation performance. The results demonstrate that the innovation network of industry-university-research cooperation in the Yangtze River Economic Zone and their intermediate centrality of each subject is relatively low. Nevertheless, a few nodes, such as the Zhejiang Geely Group, have established a long-term cooperation relationship with each other and the "grouping" of a few nodes in the nucleus. The size of the subnetwork, with the core of a few nodes "grouped" together, is constantly expanding so that subjects with a high degree of intermediate centrality have a clear advantage in accessing resources.

(3) The structural hole limit system is a negative indicator. The smaller the structural hole limit, the more the innovation subject in the structural hole position 
TABLE 3: Regression results.

\begin{tabular}{|c|c|c|c|c|c|}
\hline Variables & Model 1 & Model2 & Model3 & Model4 & Model5 \\
\hline INC & $\begin{array}{c}6583.868^{* * *} \\
(0.000)\end{array}$ & $\begin{array}{c}6656.707^{* * *} \\
(0.000)\end{array}$ & $\begin{array}{c}6416.767^{* * *} \\
(0.000)\end{array}$ & $\begin{array}{c}5483.048^{* * *} \\
(0.000)\end{array}$ & $\begin{array}{c}5488.001^{* * *} \\
(0.000)\end{array}$ \\
\hline $\mathrm{CON}$ & $\begin{array}{c}-26.1290^{* * *} \\
(0.001)\end{array}$ & $\begin{array}{l}51.930 \\
(0.597)\end{array}$ & $\begin{array}{c}-24.453^{* * *} \\
(0.001)\end{array}$ & $\begin{array}{l}-8.587 \\
(0.386)\end{array}$ & $\begin{array}{l}-8.128 \\
(0.243)\end{array}$ \\
\hline COS & $\begin{array}{c}1.1490^{* * *} \\
(0.000)\end{array}$ & $\begin{array}{c}1.1531^{* * *} \\
(0.000)\end{array}$ & $\begin{array}{c}1.763^{* * *} \\
(0.000)\end{array}$ & $\begin{array}{c}1.544^{* * *} \\
(0.000)\end{array}$ & $\begin{array}{c}1.545^{* * *} \\
(0.000)\end{array}$ \\
\hline $\mathrm{CON}^{2}$ & & $\begin{array}{c}-41.444 \\
(0.426)\end{array}$ & & & \\
\hline $\cos ^{2}$ & & & $\begin{array}{c}-0.003^{* * *} \\
(0.000)\end{array}$ & $\begin{array}{c}-0.003^{* * *} \\
(0.000)\end{array}$ & $\begin{array}{c}-0.003^{* * *} \\
(0.004)\end{array}$ \\
\hline INA & & & & $\begin{array}{c}5.283^{* * * *} \\
(0.000)\end{array}$ & $\begin{array}{c}5.348^{* * *} \\
(0.000)\end{array}$ \\
\hline GRP & & & & & $\begin{array}{c}-6.66 e-06 \\
(0.830)\end{array}$ \\
\hline $\mathrm{R} \& D$ & & & & & $\begin{array}{c}-328.239 \\
(0.830)\end{array}$ \\
\hline Constant & $\begin{array}{c}33.840^{* * *} \\
(0.000)\end{array}$ & $\begin{array}{l}-1.713 \\
(0.970)\end{array}$ & $\begin{array}{c}30.487^{* * *} \\
(0.000)\end{array}$ & $\begin{array}{c}2.129 \\
(0.782)\end{array}$ & $\begin{array}{c}4.006 \\
(0.614)\end{array}$ \\
\hline$R^{2}$ & 0.4147 & 0.4152 & 0.4219 & 0.5255 & 0.5267 \\
\hline$F$ & $\begin{array}{c}165.33^{* * *} \\
(0.000)\end{array}$ & $\begin{array}{c}124.09^{* * *} \\
(0.000)\end{array}$ & $\begin{array}{c}127.52^{* * *} \\
(0.000)\end{array}$ & $\begin{array}{c}154.63^{* * *} \\
(0.000)\end{array}$ & $\begin{array}{c}110.67^{* * *} \\
(0.000)\end{array}$ \\
\hline
\end{tabular}

Note. ${ }^{* * *}$ indicates significance level $p$ is less than 0.01 .

of the network. From model 1, it can be seen that the coefficient of the structural hole limit system is negative, but it has a significant $p$ value less than 0.01 . These demonstrate that the structural hole limit system positively affects the subjects' performance within the innovation network of industry-university-research cooperation in the automotive industry in the Yangtze River Economic Belt. This outcome indicates that the performance of the nodes in the network benefits from the structural hole limit system. However, all the coefficients of the structural hole limit system are not significant. It indicates that the nodes with excessive structural hole limits will relatively lose the innovation network of the automotive industry-university-research cooperation in the Yangtze River Economic Belt. Hypothesis H2 was not verified.

(4) From models 1 and 3, it can be seen that the first term coefficient of cooperation intensity is positive, and the second term coefficient is negative. The corresponding $p$ value for both coefficients is less than 0.01 and 0.05 , respectively, indicating significance levels. Because the number of cooperation is a positive integer and the curve's apex lies to the right of the vertical coordinate, the cooperation intensity and the subject's innovation performance show an apparent inverted U-shaped relationship. The cooperation intensity positively affects the subject's innovation performance. First, when the cooperation intensity reaches a threshold value, the direction of the influence changes, and hypothesis $\mathrm{Hb} 2$ is verified. Although there are subjects in the network with small cooperation, they have an excessive total number of collaborations. Notwithstanding, repetitive cooperation can reduce the cost of risk to a certain extent. It is not conducive to the acquisition of heterogeneous resources, which might not be favorable for enhancing the innovation performance of the subject.

(5) Model 4 and model 5 include the control variables-innovation activity, GRP per capita, and R\&D funding intensity. The coefficient of the innovation activity is positive. The significance level of pvalue less than 0.01 shows that innovation activity plays a significant positive effect on the innovation performance of the subject. When a subject is active in the network and frequently establishes cooperative innovation relationships with other subjects, it responds to the market changes sensitively and obtains new information and resources. It further maintains the continuity of innovation and thus helps the subject improve its innovation performance. One of the possible reasons for this is that there are many new edge nodes in different cities each year, and the innovation performance of each city is polarised, so the impact of GRP per capita and R\&D intensity on the innovation performance of each individual subject in the overall network is not significant.

This study proposes that the results may differ if only the "leading" players in each region are selected for comparison; hence, further research would be conducted to determine different results in the future.

\section{Conclusion}

This study outlines the following conclusions and recommendations for further development of the enterprise network structure. 
Firstly, a response analysis focusing on resource-based theory must be encouraged. Enterprises are a collection of resources and focus on heterogeneous strategic resources, i.e., valuable, scarce, incomplete imitation, and incomplete substitution. Only by having heterogeneous strategic resources can different companies maintain a sustainable competitive advantage and stand out in the same industry. Therefore, the subjects of the IURCIN, especially the enterprises, need access to heterogeneous strategic resources to ensure their sustainable development to innovate and adapt to the trend of the times constantly. From the analysis, it can be seen that the trend of the evolution of the IURCIN forms a large number of nodes at the edge of the network. Enterprises need to cooperate with the suppliers of knowledge, talent, and other innovation bodies to increase their frequency of cooperation. This cooperation can help absorb new knowledge and technology from universities, research institutes, and other organizations. This cooperation will provide a constant stream of intellectual support for their technological innovation.

In the long run, strategic alliances should take on the role of innovation, both as intermediaries and as participants and implementers of innovation and development of industries, to promote the deep integration and development of "government, industry, academia, research, and finance." This suggestion is in congruence with the studies conducted by [44]. While building a strategic alliance together, it is necessary to consider each subject's core strengths and specific strengths to implement the principles of complementary advantages, comparable strengths, and cultural compatibility to achieve sustainable development of the alliance.

Secondly, the study revealed that since the 1990s, the technological change of enterprises has been accelerating, and the cycle of product renewal has been shortening based on social network theory analysis. Collaborative innovation among various innovation agents has become the priority of the new era. Furthermore, the study found that intermediate centrality and structural hole-limit systems have a significant positive contribution to the innovation performance of the subject, and the intensity of cooperation has a significant inverted U-shaped relationship with the innovation performance of the subject. This result shows a large amount of simple peer-to-peer collaboration in the innovation network of the automotive industry in the Yangtze River Economic Zone, and there are also many independent innovation subjects outside the network.

5.1. Recommendations. This study recommends that the government strengthens the overall network characteristics, support, and guide the core nodes within the Yangtze River Economic Belt. It was revealed in this study that the $\mathrm{Au}-$ tomotive IURCIN with high centrality occupies the structural hole position. It relies on these core nodes' radiation effect and cohesion to absorb more edge subjects and external subjects of the network to participate in the whole IURCIN to enhance the overall network. This will promote the comprehensive connectivity of the network, making the nodes between the network more closely connected and the range of partners more extensive.

In addition, while supporting the core nodes, the government needs to increase its support for other subjects to encourage each innovation subject in the IURCIN to develop its sense of collaboration and innovation and its ability to learn and exchange information and further promote its own collaboration and innovation ability to catch up with the pace of innovation in this intellectual property era.

Again, policies from the government and other affiliated bodies should be based on reciprocity and mutual survival. The cooperation between industry, universities, and research institutes in applying for patents is one way to deal with each innovation subject. Dealing with each other will inevitably reduce costs and the distribution of benefits. The final distribution of benefits for each subject has an important impact on the in-depth cooperation between industry, universities, and research institutes. Hence, reciprocal cooperation thinking benefits the in-depth cooperation of various innovative subjects in industry-university-research cooperation.

Furthermore, in today's unpredictable market environment, each innovation player must adopt an appropriate level of thinking and reciprocity when entering into various agreements. This strategy will facilitate the smooth promotion of cooperation, rather than just demanding perfect contracts that are all-encompassing. Most companies, such as Huawei, adopted the strategic idea of reciprocal collaborative $R \& D$, which was vigorously pursued with some degree of success, thus setting an example and guiding the progress of mutual collaboration for other industries and enterprises.

Finally, during the negotiation period of cooperation, the innovation subjects of each party should ensure the symmetry of information between the partners through several face-toface interactions and communications and gradually build up a trusting relationship to lay a good foundation for the signing of cooperation agreements. During the formal cooperation period, it is necessary to reduce cohesion and conflicts and improve the balanced contribution of members.

5.2. Practical Implication. In practice, the frequency of seminars and exchanges and collaborative experiments can be increased to better form an interactive influence on each other's innovative ideas, thoughts, and ways of conduct, to effectively enhance the innovative capacity of both partners to ensure the increase of cooperation intensity. The collaboration of a series of economic activities implemented in a standard cooperation style between the innovation subjects of industry-university-research cooperation will be a complex but efficient innovation model. Also, the guidance and supervision of the government are still indispensable in this process. The government needs to play an active role as a trigger to strengthen the awareness and conduct of each innovation body in reciprocal cooperation and adopt a more forward-looking legislative and regulatory mechanism to ensure the effective implementation of industry-universityresearch cooperation. 


\section{Data Availability}

The data used for this study are available and would be supplied upon request.

\section{Conflicts of Interest}

The authors declare no conflicts of interest.

\section{Authors' Contributions}

All authors contributed equally to this work.

\section{Acknowledgments}

This research was supported by the Key Research Base of Universities in Jiangsu Province for Philosophy and Social Science "Research Center for Green Development and Environmental Governance and Social Science Funding Project of Jiangsu Province under grant no. 18GLB024.

\section{References}

[1] Z. Li, Z. Ma, W. Shi, and X. Qian, "Research on medicine distribution route optimization for community health service institutions," Mathematical Problems in Engineering, vol. 2016, Article ID 6153898, 7 pages, 2016.

[2] H. Bathelt, A. Malmberg, and P. Maskell, "Clusters and knowledge: local buzz, global pipelines and the process of knowledge creation," Progress in Human Geography, vol. 28, no. 1, pp. 31-56, 2004.

[3] M. E. J. Newman and D. J. Watts, "Scaling and percolation in the small-world network model," Physical Review E, vol. 60, no. 6, pp. 7332-7342, 1999.

[4] D. J. Watts and S. H. Strogatz, "Collective dynamics of 'smallworld' networks," Nature, vol. 393, no. 6684, pp. 440-442, 1998.

[5] L. Li, Z. Xu, and G. Jiping, "Study on the knowledge transfer in the university-industry cooperation based on the small-world network," Science \& Technology Progress and Policy, vol. 27, no. 3, pp. 5-8, 2010.

[6] Z. Minzing, Y. Yongfu, and Z. Lei, "An empirical study on the impact of firm innovation performance based on network structure perspective," Statistics and Decision Making, vol. 10, pp. 183-186, 2013.

[7] Y. Zhao and G. X. Wang Qi, "Research on innovation performance of inter-firm innovation network of strategic alliance," East China Economic Management, vol. 28, no. 1, pp. 108-112, 2014.

[8] Q. Geqi, G. Xia, and C. Jieqiong, "The impact of industry university research collaboration innovation network structure on firm innovation performance in China's ICT industry," Science Research Management, vol. 37, no. S1, pp. 110-115, 2016.

[9] Y. Shi and J. C. Guan, "Small-world network effects on innovation: evidences from nanotechnology patenting," Journal of Nanoparticle Research, vol. 18, no. 11, 2016.

[10] A. Goerzen, "Alliance networks and firm performance: the impact of repeated partnerships," Strategic Management Journal, vol. 28, no. 5, pp. 487-509, 2007.

[11] C. C. Phelps, "A longitudinal study of the influence of alliance network structure and composition on firm exploratory innovation," Academy of Management Journal, vol. 53, no. 4, pp. 890-913, 2010.

[12] Z. Y. Hui Qing, "The relationship among innovation network, knowledge integration and technology innovation in cooperation of industry university and research institute," Science and Technology and the Economy, vol. 123, no. 3, pp. 4-9, 2010.

[13] C. Beaudry and A. Schiffauerova, "Impacts of collaboration and network indicators on patent quality: the case of Canadian nanotechnology innovation," European Management Journal, vol. 29, no. 5, pp. 362-376, 2011.

[14] E. Bakshy, I. Rosenn, C. Marlow, and L. Adamic, "The role of social networks in information diffusion," in WWW'12 Proceedings of the 21st Annual Conference on World Wide Web, pp. 519-528, Lyon, France, April 2012.

[15] J.-P. Onnela, J. Saramäki, J. Hyvönen et al., "Structure and tie strengths in mobile communication networks," Proceedings of the National Academy of Sciences, vol. 104, no. 18, pp. 7332-7336, 2007.

[16] Y. Zhao and G. Xiawan, "Structural hole degree, inter-firm network and innovation performance - evidence from Chinese domestic audio industry strategic alliance," Science \& Technology Progress and Policy, vol. 29, no. 17, pp. 76-81, 2012.

[17] D. Yingying and X. Linlin, "Empirical research on innovation networks of industry - university - research institute of ocean energy industry - the view of network structure," Journal of Industrial Technological Economics, vol. 259, no. 5, pp. 29-40, 2015.

[18] L. Guowei and Y. Zhengyi, "The influence of regional industry-university-research cooperation innovation network structure on knowledge diffusion--based on electronic information patent data of Guangxi from 2000-2013," Science and Technology Progress and Policy, vol. 32, no. 23, pp. 36-42, 2015.

[19] C. Zhou, G. Zeng, F. Wang, Y. Si, and Z. Mi, "Innovation network structure and innovative performance: a study of China's electronic information industry," Scientia Geographica Sinica, vol. 37, no. 5, pp. 661-671, 2017.

[20] M. G. Everett and T. W. Valente, "Bridging, brokerage and betweenness," Social Networks, vol. 44, pp. 202-208, 2016.

[21] M. Kimura, K. Saito, R. Nakano, and H. Motoda, "Social computing and behavioral modeling," Social Computing and Behavioral Modeling, pp. 138-145, 2009.

[22] L. Zheng-qiang and W. Ying, "Analysis of influence of geographical vicinity and cognitive vicinity on creative achievement - empirical research of medium and small sized high technological enterprises based on knowledge acquisition," Seeking Truth, vol. 42, no. 6, pp. 39-46, 2015.

[23] L. Bin, T. Huimin, W. Yufeng, and T. Xiao-li, "Effect of geographical proximity on the formation of cooperation partnership and technological innovation performance in universities," Research and Development Management, vol. 28, no. 1, pp. 121-131, 2016.

[24] H. Chen and F. Xie, "How technological proximity affect collaborative innovation? An empirical study of China's Beijing-Tianjin-Hebei region," Journal of Management Analytics, vol. 5, no. 4, pp. 287-308, 2018.

[25] Z. Yan, W. Qi, and Z. Xiangjie, "Impact of network vicinity and geographical proximity to knowledge transfer performance," Science Research Management, vol. 37, no. 1, pp. 129-136, 2016.

[26] C. Zifeng and G. Jiancheng, "The impacts of small worlds on innovation," Chine Se Journal of Management Science, vol. 17, no. 3, pp. 115-120, 2009. 
[27] C. Wei, Z. Yong-chao, and T. Shi, "Empirical research on innovation networks consisting of industry - university research institute in regional equipment manufacturing industry: a perspective of network structure and network cluster," China Soft Science, vol. 2, pp. 96-107, 2012.

[28] Y. Yi and H. Junhui, "Industry-university-research cooperation network's small-world、Knowledge Base and enterprise innovation," Science and Technology Management Research, vol. 37, no. 19, pp. 139-146, 2017.

[29] S. Yang and L. Nan, "The influence of R\&D team knowledge exchange network centrality on knowledge diffusion and its empirical study," Intelligence Theory and Practice, vol. 33, no. 4, pp. 28-31, 2010.

[30] E. Muller and R. Peres, "The effect of social networks structure on innovation performance: a review and directions for research," International Journal of Research in Marketing, vol. 36, no. 1, pp. 3-19, 2019.

[31] H. Wang, Y. Zhao, B. Dang, P. Han, and X. Shi, "Network centrality and innovation performance: the role of formal and informal institutions in emerging economies," Journal of Business \& Industrial Marketing, 2019.

[32] J. Wang, N. Yang, Y. Zhang, and Y. Song, "Dynamics of firm's network community associations and firm's innovation performance," Technology Analysis \& Strategic Management, vol. 32, no. 3, pp. 239-255, 2020.

[33] T. Juying, Enterprise Network Centrality and TechnologicalInnoVation Empirical Research The Intermediary Role of Organizational Learning Capability, pp. 1-43, Nanjing University of Aeronautics and Astronautics, Nanjing, China, 2013.

[34] B. McEvily and A. Zaheer, "Bridging ties: a source of firm heterogenity in competitive capabilities," Strategic Management Journal, vol. 1156, no. July, pp. 1133-1156, 1999.

[35] Z. Xiao and Q. Zheng, "Structural hole of knowledge and collaboration network on technology innovation," Soft Science, vol. 27, no. 12, pp. 58-62, 2013.

[36] L. Dajin, W. Haifeng, and L. Yuan, "Innovation policy performance research based on social network effects," Science of Science and Management of S.\&.T, vol. 38, no. 11, pp. 10-19, 2017.

[37] Y. Chunxia, Y. Xiang, and L. Wei, "Research on multidisciplinary knowledge network of Chinese," Journal of Intelligence, vol. 32, no. 4, pp. 113-120, 2013.

[38] Y. Ma, F. Liu, and W. Y. Jiang Binbin, "The influence of scope and depth of firms'inter - organizational R and D collaboration on enterprise innovation performance: an empirical analysis based on Chinese industrial enterprises database," Science Research Management, vol. 35, no. 6, pp. 33-40, 2014.

[39] A. Gambardella, P. Giuri, and A. Luzzi, "The market for patents in europe," SSRN Electronic Journal, 2011.

[40] Z. Jian-ji and Z. Gang, "Spatial measurement of innovation: data and indicators," Economic Geography, vol. 29, no. 8, pp. 1250-1255, 2009.

[41] J. Singh, "Collaborative networks as determinants of knowledge diffusion patterns," Management Science, vol. 51, no. 5, pp. 756-770, 2005.

[42] J. S. Coleman, "Social capital in the creation of human capital," in Knowledge and Social Capital: Foundations and Applications, Butterworth-Heinemann, Oxford, UK, 1988.

[43] Y. Hongbin, "A study of the influence of structural holes on product innovation performance from the perspective of knowledge search and transfer," Scientific Research Management, vol. 37, no. 4, pp. 9-15, 2016.
[44] L. Mingxing, Z. Mengjuan, H. Cheng, S. Jialu, and Z. Minran, "Innovation research on operation model of patent pool concerning intellectual property intensive industry," Science and Technology Progress and Policy, vol. 33, no. 22, pp. 64-68, 2016. 